\title{
Next-generation mTOR inhibitors in clinical oncology: how pathway complexity informs therapeutic strategy
}

\author{
Seth A. Wander, ${ }^{1,2}$ Bryan T. Hennessy, ${ }^{3}$ and Joyce M. Slingerland ${ }^{1,4}$ \\ ${ }^{1}$ Braman Family Breast Cancer Institute, Sylvester Comprehensive Cancer Center, and ${ }^{2}$ Graduate Program in Cancer Biology, \\ University of Miami Miller School of Medicine, Miami, Florida, USA. ${ }^{3 B e a u m o n t ~ H o s p i t a l ~ a n d ~ R o y a l ~ C o l l e g e ~ o f ~ S u r g e o n s ~ o f ~ I r e l a n d, ~ D u b l i n, ~ I r e l a n d . ~}$ \\ ${ }^{4}$ Departments of Medicine and of Biochemistry and Molecular Biology, University of Miami Miller School of Medicine, Miami, Florida, USA.
}

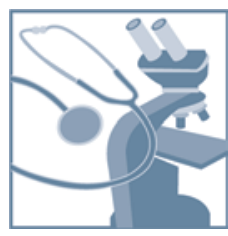

\begin{abstract}
Mammalian target of rapamycin (mTOR) is a PI3K-related kinase that regulates cell growth, proliferation, and survival via mTOR complex 1 (mTORC1) and mTORC2. The mTOR pathway is often aberrantly activated in cancers. While hypoxia, nutrient deprivation, and DNA damage restrain mTORC1 activity, multiple genetic events constitutively activate $m$ TOR in cancers. Here we provide a brief overview of the signaling pathways up- and downstream of mTORC1 and -2, and discuss the insights into therapeutic anticancer targets - both those that have been tried in the clinic with limited success and those currently under clinical development - that knowledge of these pathways gives us.
\end{abstract}

\section{Basics of the mammalian target of rapamycin signaling network}

Mammalian target of rapamycin (mTOR) is a serine/threonine kinase and member of the PI3K-related kinase (PIKK) family, which includes PI3K, DNA protein kinase (DNA-PK), and ataxia telangiectasia mutated (ATM). mTOR is a master integrator of signals governing protein and lipid biosynthesis and growth factor-driven cell cycle progression (Figure 1). It functions to regulate these processes in two cellular complexes. mTOR complex 1 (mTORC1) includes mTOR regulatory-associated protein of mTOR (Raptor), mLST8, and proline-rich Akt substrate 40 (PRAS40) (1) and is allosterically inhibited by the macrolide antibiotic rapamycin (2). Rapamycin binds irreversibly to mTORC1 and impairs substrate recruitment. mTOR forms a second complex, mTORC2, with rapamycin-insensitive companion of mTOR (Rictor), mLST8, and stress-activated MAPK-interacting protein 1 (Sin1) (3). Although rapamycin does not directly inhibit mTORC2, in U937 lymphoma cells, PC3 prostate cancer cells, and PC3 xenografts, prolonged rapamycin treatment inhibits mTORC2 action, likely via irreversible mTOR sequestration (4). While most mTORC1 and -2 components differ, DEP domain-containing mTOR-interacting protein (DEPTOR) binds and inhibits both complexes. Upregulation of DEPTOR expression or activity may present a novel therapeutic strategy for mTOR kinase inhibition (5).

mTOR activity is intricately linked to PI3K signaling (Figure 1 and refs. 6, 7). Receptor tyrosine kinases (RTKs) for IGF-1, HGF, and EGF all signal through PI3K to activate phosphoinositidedependent protein kinase-1 (PDK1). In turn, PDK1 phosphorylates AGC family kinases (homologs of protein kinases A, G, and C), including AKT, serum/glucocorticoid-regulated kinase 1 (SGK1), and ribosomal S6 kinase, $90 \mathrm{kDa}$, polypeptide 1 (RSK1), all of which require a second stimulatory phosphorylation to become activated. mTORC2 mediates this second phosphoryla-

Conflict of interest: The authors have declared that no conflict of interest exists. Citation for this article: JClin Invest. 2011;121(4):1231-1241. doi:10.1172/JCI44145. tion on $\operatorname{AKT}(8,9)$; both mTORC1 and mTORC2 can do so for SGK1 $(10,11)$; and MAPK1 and MAPK3 both do so for RSK1 (12). Thus, PI3K and mTOR pathways act together to promote cell growth, division, and survival: AKT activates antiapoptotic mechanisms and the cell cycle; SGK1 regulates insulin and energy metabolism; and RSK1 activates mitogenic transcription factors (12-14).

The tuberous sclerosis 1 (TSC1)/TSC2 complex inhibits mTOR/ Raptor by keeping the mTORC1 activator Ras homolog enriched in brain (Rheb) in its inactive state $(1,15)$. Importantly, AKT is not only a substrate of mTORC2, but also indirectly activates mTORC1 by phosphorylating and inhibiting TSC2 (16-18). TSC1/2 functions as a molecular hub, integrating growth factor and energy-sensing pathways to regulate mTOR/Raptor activity (Figure 1). Mitogens inactivate TSC1/2 via ERK-, AKT-, and RSK1mediated phosphorylation of TSC2, to drive mTORC1-dependent protein and lipid biosynthesis $(17,19-21)$. RSK1 also phosphorylates and activates Raptor (22).

In normal tissues, TSC $1 / 2$ is activated by adverse conditions such as DNA damage, hypoxia, and nutrient deprivation to inhibit mTORC1-mediated biosynthetic processes when substrate availability is limited. Hypoxia, via HIF1 $\alpha$, activates REDD1, which antagonizes AKT-mediated TSC2 inactivation (23-25). Nutrient deprivation activates LKB1, which drives AMP-activated protein kinase (AMPK) to phosphorylate and activate TSC2 (26-28). DNA damage also activates AMPK via the tumor suppressor p53 (29). AMPK can also phosphorylate Raptor, leading to its sequestration by 14-3-3 (30). Thus, DNA damage and energy stress drive AMPK to activate TSC $1 / 2$ and inhibit mTORC1 via multiple mechanisms.

The intricate regulation of TSC $1 / 2$ highlights the importance of mTORC1 in cellular homeostasis. mTORC1 stimulates protein biosynthesis by phosphorylating ribosomal protein S6 kinase 1 (S6K1) to activate ribosomal biogenesis and by phosphorylating eukaryotic initiation factor 4E-binding protein 1 (4EBP1), thereby activating eukaryotic initiation factor $4 \mathrm{E}$ (eIF4E) to promote protein translation (31). mTOR also stimulates lipid biogenesis, 


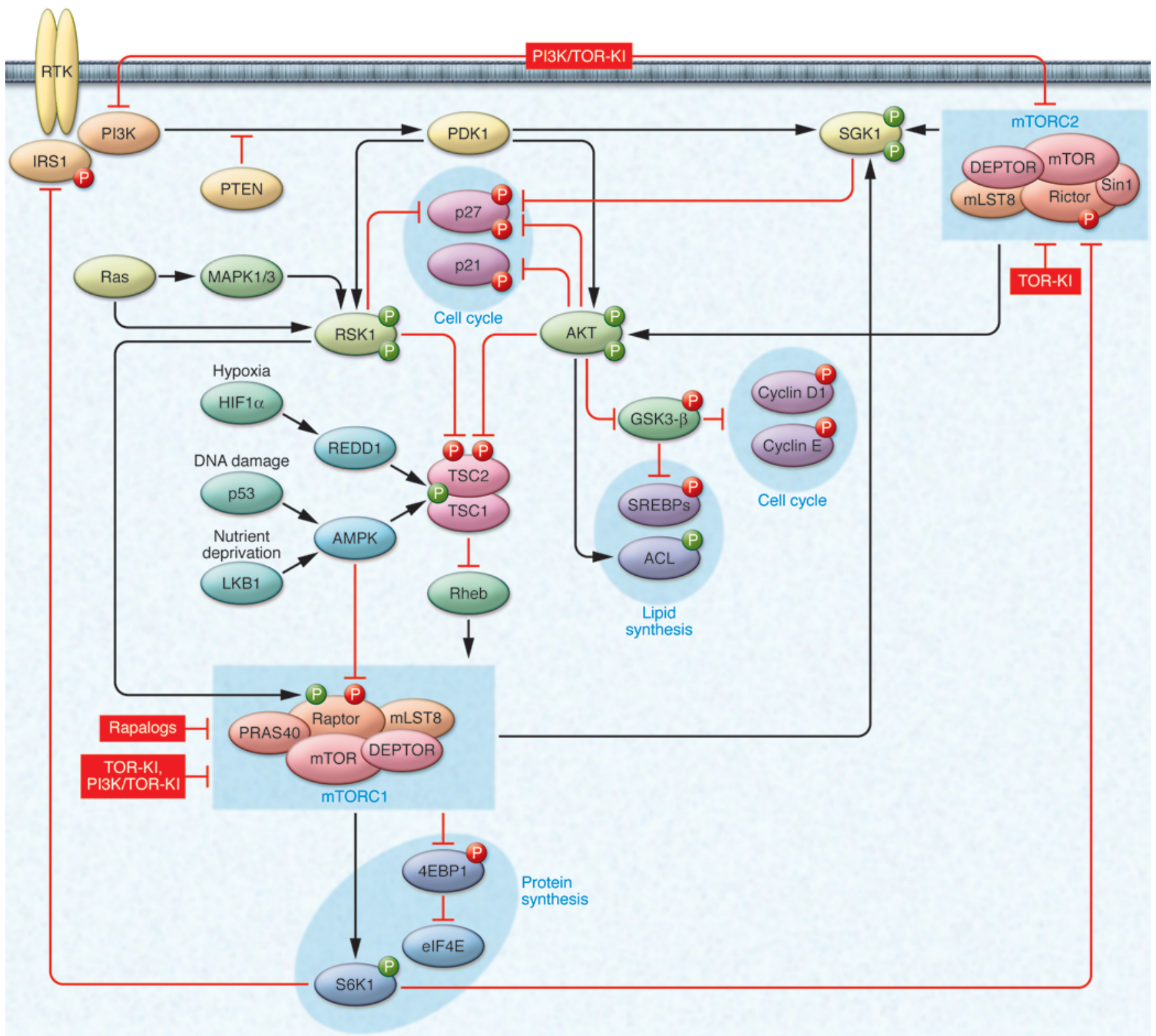

Figure 1

Targeting the mTOR signaling network for cancer therapy. mTOR-based targeting strategies are presented in the context of the PI3K/mTOR signaling network. Pathways activating mTOR via RTKs and PI3K are shown together with effectors regulating protein and lipid biosynthesis and cell cycle. mTORC1 and mTORC2 modulate cell cycle via effects on Cdk inhibitors p21 and p27, cyclin D1, and cyclin E; SREBPs and ACL regulate lipid biosynthesis downstream of AKT; mTORC1 phosphorylates 4EBP1 and S6K1 to activate critical drivers of global protein translation. Also represented are important feedback pathways whereby mTORC1 reduces signaling through PI3K and mTORC2: S6K1 phosphorylates IRS1, promoting its proteolysis; S6K1 phosphorylates Rictor to inhibit mTORC2-dependent AKT activation. The TSC1/2 complex serves as a relay center for tumor microenvironmental queues. Oncogenic PI3K/PDK1 and Ras/MAPK signaling cooperate to reduce TSC1/2 activity. Hypoxia (via HIF1 $\alpha$ ), DNA damage (via p53), and nutrient deprivation (via LKB1) all activate TSC1/2 to restrain mTORC1 and biosynthetic processes in normal tissue. These pathways are often inactivated during tumorigenesis. Rapalogs are mTORC1-specific inhibitors. TOR-KIs more potently inhibit both mTOR complexes. Dual PI3K/TOR-KIs additionally block upstream signaling via PI3K. Green circles represent stimulatory phosphorylations; red circles, inhibitory phosphorylations.

which is required for both membrane synthesis and modification of mitogenic signal transducers (32). While mTORC1 is best understood for its role in the activation of protein biosynthesis, both mTORC1 and mTORC 2 activate cell cycle progression via the AGC kinases (reviewed in refs. 33, 34, and see Figure 1). mTORC2, via AKT, increases cyclin D1 transcription and trans- lation, and inhibits glycogen synthase kinase-3- $\beta$-mediated (GSK3- $\beta$-mediated) cyclin D1 and cyclin E proteolysis $(33,35)$. AKT phosphorylates the forkhead transcription factor AFX to inhibit cyclin-dependent kinase inhibitor 1B (CDKN1B) transcription (36). AKT also phosphorylates the Cdk inhibitors p21 and p27 to impair their actions $(33,37)$. 
Here we review how investigation of this complex mTOR signaling network has revealed important mechanisms contributing to human tumorigenesis and stimulated development of mTORtargeted anticancer therapies. Despite the limited clinical success of the first-generation drugs, rapamycin and its analogs (which are known as rapalogs), biological insights into molecular signaling arising from their use have informed pharmacological design of second-generation drugs that target mTOR kinase activity, the mTOR kinase inhibitors (TOR-KIs).

\section{mTOR signaling in cancer}

Crosstalk among mTORC1, mTORC2, and PI3K normally ensures an elegant balance between cell growth and division (Figure 1). Given this, it is perhaps not surprising that disruption, either upor downstream of mTOR, is seen in many tumor types.

Upstream of $m$ TOR in cancer. Aberrant $\mathrm{PI} 3 \mathrm{~K} / \mathrm{mTOR}$ activation is commonly observed in cancers (7) and can result from amplification of, or activating mutations in, genes encoding the upstream RTKs, components of PI3K, or effector kinases (38). PIK3CA, which encodes the catalytic $\mathrm{p} 110 \alpha$ subunit of PI3K, is the most frequently mutated kinase in human cancer (39). Moreover, the gene encoding phosphatase and tensin homolog (PTEN), which normally restrains PI3K activity, is frequently deleted or inactivated (7). RSK1 hyperactivation due to RTK-dependent oncogenic Ras/MAPK and $\mathrm{PI} 3 \mathrm{~K} / \mathrm{PDK} 1$ pathway activation is also observed in cancers (40).

In tumors, the TSC $1 / 2$-activating pathways discussed above (in "Basics of the mammalian target of rapamycin signaling network") are often disrupted (41): inactivating mutations of the P53 and $L K B 1$ tumor suppressor-encoding genes are common, while angiogenesis and re-oxygenation reduce signaling via HIF1 $\alpha$ and REDD1. Heritable mutations affecting either TSC1 or TSC2 give rise to tuberous sclerosis syndrome, which is characterized by multiple benign tumors, including angiofibroma of the skin, lymphangioleiomyoma of the lungs, renal angiomyolipoma, and astrocytomas of the brain (41). While TSC1 and TSC2 mutations are rare in sporadic human cancers (42-44), reduced TSC1 or TSC2 levels have been observed (45-48). Mutational inactivation of another tumor suppressor, neurofibromatosis 1 (NF1), which encodes a Ras-GAP, upregulates Ras-GTP levels leading to activation of MEK/MAPK and RSK1, which in turn inactivates TSC1/2 (49). Finally, oncogenic MEK/ MAPK activation by BRAF in melanoma was recently shown to inhibit LKB1 binding to AMPK1 and thereby AMPK1 activation (50, 51). All of these events impair the ability of the TSC1/TSC2 complex to inhibit mTOR/Raptor in response to nutrient and oxygen deprivation and DNA damage, resulting in $\mathrm{mTORC} 1$ hyperactivation.

The different genetic lesions that mediate mTORC1 activation in cancer have different consequences: PTEN loss uncouples mTORC1 activation from growth factor signaling (i.e., PI3K/ MAPK signaling), leaving bioenergetic sensing via LKB1 and AMPK intact (52); LKB1 mutations permit mTORC1 activation despite nutrient deprivation in poorly vascularized tumors; and P53 mutations uncouple DNA damage from the inhibition of bioenergetic processes and cell cycle arrest.

mTOR studies have also revealed a new link between obesity and increased cancer risk. Data from experimental animals and humans show that mTORC1 is activated by a high-fat diet (53) and by branched-chain amino acids present in obese individuals (54). Interestingly, metformin, an oral hypoglycemic agent used to treat type 2 diabetes, was recently shown to activate AMPK via LKB1 (55). It has therefore been suggested that metformin may have anticancer effects via AMPK-mediated mTORC1 inhibition (56). A recent phase I trial of metformin with temsirolimus demonstrated disease stabilization (57), and clinical trials combining metformin with newer TOR-KIs warrant consideration.

Downstream of $m$ TOR in cancer. $\mathrm{mTOR}$ drives cancer growth by activating the lipid and protein biosynthesis needed for robust tumor expansion. This occurs via deregulated signal transduction and the resulting hyperactivation of the critical mTORC1 effectors S6K1 and eIF4E. Oncogenic mTORC1 and mTORC2 activation also drives cell proliferation via increases in cyclin D1 and cyclin E and loss of the restraining effects of p21 and p27 on cell cycle as noted above. Recent work links oncogenic PI3K/mTOR activation with cancer cell motility via $\mathrm{p} 27$. AKT, SGK1, and RSK1 cooperate to phosphorylate p27 at T157 and T198, which impairs nuclear p27 import (10, 58-62), causing cytoplasmic p27 to accumulate in cancer cells and bind RhoA (63). This inhibits RhoA-ROCK1, causing actin cytoskeleton destabilization and increased cell motility and metastasis (63-65). SGK action on p27 may underlie the observation that SGK3, a kinase closely related to SGK1, promotes anchorageindependent tumor growth (66). While the normal physiologic role for this is not clear, in cancers, constitutive PI3K/mTOR mislocalizes $\mathrm{p} 27$ to cytoplasm, thereby reducing Cdk inhibition by $\mathrm{p} 27$, and increases $\mathrm{p} 27-\mathrm{RhoA}$ binding to enhance tumor metastasis.

\section{Rapamycin and rapalogs as anticancer therapies}

Biologic investigation of the PI3K/mTOR signaling network has complemented the identification of genetic mutations in specific cancers to inform the development of clinical therapies targeting the network. Initial observations of network activation in human tumors led to the preclinical and clinical development of rapamycin and its analogs - allosteric, irreversible inhibitors of Raptor-bound mTOR - as anticancer therapies. Their investigation as anticancer therapies was aided by the fact that rapamycin had been FDA approved for many years as an immunosuppressant to prevent organ transplant rejection, and was well tolerated, despite the importance of mTORC1 in cellular homeostasis (67-69).

Rapalogs: preclinical and clinical trials. Clinical trials are currently underway to test the efficacy of rapamycin and several rapalogs, including temsirolimus (Torisel, CCI-779, Pfizer), everolimus (RAD001, Novartis), and ridaforolimus (AP23573, Ariad Pharmaceuticals), as anticancer therapies (ref. 70 and Table 1). By late 2010, the U.S. NCI website ClinicalTrials.gov listed more than 160 mTOR-directed clinical trials underway. In a large, multicenter phase III trial, temsirolimus prolonged overall survival of patients with metastatic renal cell carcinoma (RCC) compared with other treatments (71), leading to FDA approval of temsirolimus in 2007 for metastatic RCC. This study validated mTOR as a therapeutic target in cancer. Everolimus also showed efficacy in a placebo-controlled phase III trial in RCC (72) and was FDA approved in 2009.

Rapalogs have shown promise in several other malignancies that are often refractory to standard chemotherapies. Temsirolimus yielded a $22 \%$ overall response rate (ORR, which represents complete or partial responses divided by the number of patients treated) in a phase III trial for refractory mantle cell lymphoma, in contrast to only $2 \%$ for investigator's choice of therapy (73). Similarly, rapalogs showed single-agent activity against other types of lymphomas (74-76) and are being evaluated in phase II trials for sarcomas, endometrial cancers, and other advanced solid tumors (77-79). For example, a recent phase I study of everolimus showed promise in patients with advanced colorectal cancer (80). 


\section{Table 1}

Rapalogs: clinical development status

\begin{tabular}{|c|c|c|c|}
\hline Cancer type & Everolimus & Temsirolimus & Ridaforolimus \\
\hline Renal & $\begin{array}{l}\text { Approved, 3rd-line, single-agent; } \\
\text { phase III, 2nd-line + bevacizumab; } \\
\text { phase III, adjuvant, single agent }\end{array}$ & $\begin{array}{l}\text { Approved, 1st-line, single-agent, } \\
\text { high-risk patients; } \\
\text { phase III + bevacizumab }\end{array}$ & \\
\hline Non-Hodgkin lymphoma & $\begin{array}{l}\text { Phase III, 1st-line, maintenance } \\
\text { (therapy given during remission } \\
\text { to prevent relapse), diffuse large } \\
\text { B cell lymphoma }\end{array}$ & $\begin{array}{l}\text { Phase III, 3rd-line, mantle cell } \\
\text { Iymphoma }\end{array}$ & \\
\hline Pancreatic neuroendocrine & $\begin{array}{l}\text { Phase III, single-agent; } \\
\text { phase III + octreotide }\end{array}$ & & \\
\hline Gastric & Phase III, 2nd-line, single-agent & & \\
\hline Sarcoma & & & Phase III, maintenance \\
\hline Liver & $\begin{array}{l}\text { Phase III + BSC; } \\
\text { phase IIB, 1st-line + sorafenib; } \\
\text { phase IIB + TACE }\end{array}$ & & \\
\hline Breast $\left(\mathrm{ER}^{+}\right)$ & Phase III + exemestane & Failed phase III + letrozole & \\
\hline Breast $\left(H E R 2^{+}\right)$ & $\begin{array}{l}\text { Phase III, 1st-line + paclitaxel/trastuzumab; } \\
\text { phase III, 2nd/3rd-line + trastuzumab/vinorelbine; } \\
\text { phase IIB, neoadjuvant + trastuzumab }\end{array}$ & & \\
\hline Breast (HER2-) & Phase IIB, 1st-line + paclitaxel/bevacizumab & & \\
\hline Ovarian & Phase IIB + bevacizumab & & \\
\hline Head and neck & Phase IIB, adjuvant + single-agent & & \\
\hline Colorectal & Phase IIB, 1st-line + XELOX-A & & \\
\hline Glioblastoma & $\begin{array}{l}\text { Phase IIB, 1st-line } \\
\text { + temozolomide/radiotherapy }\end{array}$ & $\begin{array}{l}\text { Phase IIB, 1st-line, unmethylated } \\
\text { MGMT promoter + radiotherapy }\end{array}$ & \\
\hline Prostate (hormone resistant) & Phase IIB + bicalutamide & & Phase IIB + bicalutamide \\
\hline Non-small cell lung & & & Phase IIB, KRAS mutant \\
\hline Endometrial & & & Phase IIB, single-agent \\
\hline
\end{tabular}

BSC, best supportive care; MGMT, $\mathrm{O}^{6}$-methylguanine-DNA methyltransferase; TACE, transarterial chemoembolization; XELOX-A, bevacizumab/ capecitabine/oxaliplatin.

Not surprisingly, rapalogs have shown efficacy against proliferative syndromes resulting from mutational inactivation of either TSC1 or TSC2. Various studies in TSC patients showed that rapalogs improve facial angiofibroma, renal angiomyolipoma, and pulmonary lymphangioleiomyomatosis (81-83), and further trials are underway. Substantial regression of subependymal giant cell astrocytomas was observed with rapamycin in a phase I trial in TSC patients (84). This was followed by a phase II trial of everolimus for subependymal giant cell astrocytomas that showed reduction in seizures and tumor size (85). These striking results provide perhaps the strongest proof of concept that mTOR inhibitors will work in selected patients whose tumors are driven by mTOR signaling abnormalities.

Despite frequent PTEN loss in sporadic glioma and melanoma, rapalogs have had little efficacy in patients with these tumors (86, 87). In endometrial cancers, which have early PTEN loss, tumor regression has rarely been observed, despite stabilization of disease by rapalogs in $26 \%-44 \%$ of those treated in two small phase II studies $(78,79)$. Moreover, while breast cancers show frequent PI3K activation (7), via HER2 amplification, overexpression of IGF-1R or EGFR, PIK3CA mutation, or PTEN loss, the activity of temsirolimus (ORR,
7\%-10\%) (88) and everolimus (ORR, 12\%) (89) as single-agent therapies was disappointing in individuals with metastatic breast cancer.

Thus, while rapalogs have demonstrated some success, they have shown only modest efficacy in tumors where they were expected to provide substantial benefit. The clinical successes, notably for RCC and mantle cell lymphoma, are meaningful, since these diseases are largely resistant to standard chemotherapy. Benign tumors arising from TSC1 and TSC2 mutations may be most sensitive to rapalogs because of their greater inherent genetic stability and a lower propensity for activation of resistance mechanisms. Perhaps the most significant success of the laboratory and clinical investigation of rapalogs in cancers is that they have revealed potential causes of rapalog failure, which fostered the development of next-generation TOR-KIs.

Mechanisms underlying the limited anticancer efficacy of rapalogs. Both animal and clinical studies have shown that rapalogs are primarily cytostatic, not cytotoxic, and clinical efficacy largely reflects disease stabilization rather than regression (70). One reason for rapalog failure is that they are incomplete, substrate-selective mTORC1 inhibitors: rapalogs block the action of mTORC1 on certain substrates more effectively and more durably than others. For example, 
although rapamycin and its analogs inhibit S6K1 phosphorylation, they show only transient or no ability to block 4EBP1 phosphorylation and cap-dependent translation (90-92). The molecular mechanisms underlying this are not well understood. Thus, rapalogs only incompletely inhibit mTORC1-dependent protein synthesis, and this may contribute to resistance to rapalogs.

Rapalogs, through irreversible sequestration of mTOR, disrupt a dynamic signaling network linking mitogen and energy sensing. Another reason for rapalog failure is the existence of feedback circuits, activated by mTORC1 inhibition, that drive mitogenic signaling. For example, mTORC1 inhibition leads to feedback activation of the PI3K pathway. In normal cells, autoinhibitory feedback mechanisms limit mTORC1 and -2 signaling (Figure 1). mTORC1 activates S6K1, which promotes insulin receptor substrate (IRS) proteolysis (93). The IRS scaffold protein facilitates insulin and IGF receptor signaling to activate PI3K. mTORC1- and S6K1-mediated IRS loss dampens PI3K signaling, which in turn reduces input to mTORC1. Rapalogs block this S6K1-dependent autoinhibitory pathway (93), causing feedback activation of PI3K, promoting resistance to the effects of rapamycin and its analogs. Following everolimus treatment, biopsy specimens showed AKT activation in colon cancers (94). Rapalog-sensitive feedback mechanisms also activate other RTKs through additional scaffold proteins $(95,96)$.

Another feedback circuit exists in which mTORC1 activity, functioning via S6K1, leads to phosphorylation of Rictor to inhibit mTORC2 $(97,98)$. Rapalog-mediated mTORC1 inhibition relieves this tonic Rictor inhibition and drives mTORC2-mediated AKT activation. In addition, mTORC1 inhibition can cause feedback activation of MAPK via an S6K1/PI3K/Ras pathway. Consistent with this, MAPK activation has been observed in metastatic solid tumors following RAD001 treatment (99). Thus, the cytostatic effects of rapalogs in cancers are limited by feedback activation of PI3K, Ras/MAPK, mTORC2, and downstream AGC kinases, all of which oppose rapalog effects on protein biosynthesis and cell cycle.

Combinations targeting upstream activators to enhance rapalog efficacy. The modest clinical results of single-agent rapalog trials, with disease stabilization rather than regression being achieved, have prompted a number of combination therapy trials (Table 1). Rapalogs have shown in vitro synergism with several cytotoxic chemotherapeutic agents $(100,101)$. While rapalog/chemotherapeutic combination trials may have had little molecular rationale at their inception, recent work has provided one. p53-deficient cancers have lost a major mechanism by which DNA damage leads to mTORC1 inhibition. In normal cells, DNA damage activates AMPK via p53, and AMPK-driven TSC1/2 activation inhibits mTORC1 to permit DNA repair before cell division (29). Cells with p53 loss no longer respond to chemotherapeutic DNA damage by attenuating mTORC1 activity and arresting proliferation. This allows continued cell division despite significant DNA damage, rendering cells more sensitive to chemotherapy-induced apoptosis. Cell survival becomes mTORC1 dependent, rendering cancer cells more sensitive to combined chemo-/rapalog therapy.

Trials are underway to enhance rapalog efficacy and overcome feedback PI3K activation by combining rapalogs with antitumor agents acting upstream of mTORC1 (Table 1). Everolimus is being evaluated with a somatostatin analog, octreotide, that blocks IGF production and consequent PI3K activation. A phase II trial of everolimus and octreotide for the treatment of neuroendocrine tumors yielded an ORR of $20 \%$, a dramatic improvement over everolimus alone (102), and a phase III registration trial is now underway (Table 1). In non-small cell lung cancer, where EGFR inhibitors have modest efficacy, combinations of rapalogs with erlotinib, an EGFR tyrosine kinase inhibitor, are under investigation in phase II trials. Estrogen is known to stimulate both MAPK and PI3K, both of which contribute to mTORC1/2 activation (103). In preclinical breast cancer studies, rapalogs augmented effects of anti-estrogens, including tamoxifen, fulvestrant, and aromatase inhibitors (letrozole and exemestane) (104-106). It is not clear why combined temsirolimus and letrozole yielded no improvement over letrozole alone in one trial in metastatic estrogen receptor-positive $\left(\mathrm{ER}^{+}\right)$breast cancer (107), while everolimus appeared to complement letrozole in advanced breast cancer (108, 109). Combined aromatase and mTORC1 inhibition is being further evaluated in larger patient cohorts. Strategies combining exemestane with everolimus have been promising, as has combining HER2 blockade by trastuzumab and everolimus in HER2+ breast cancer in early clinical studies (110).

Perhaps the greatest therapeutic efficacy of rapalogs and the TORKIs will lie in their rational combination with drugs that block nodal pathways in cancer signaling and preclude feedback pathway activation, such as inhibitors of EGFR1/2, IGF-1R, PI3K, BRAF, and MEK. For example, since BRAF is frequently activated in melanoma (111), the ensuing MEK activation blocks LBK1/AMPK-driven TSC1/2 activation and keeps mTORC1 constitutively active $(50,51)$. Thus, rapalog/BRAF inhibitor combinations may prove beneficial for this tumor type. While such strategies may ultimately yield viable treatment options, dose-limiting rapalog toxicities, including skin rash, nausea, and diarrhea, may be manifest in combination with other drugs. This potential limitation and the more concerning observations that rapalogs cause only incomplete inhibition of mTORC1 signaling and lead to the unintended activation of feedback loops that drive PI3K, mTORC2, and MEK signaling have therefore stimulated a shift in drug development toward next-generation TOR-KIs and dual PI3K/mTOR catalytic site inhibitors (PI3K/TOR-KIs).

\section{Beyond rapalogs: molecular rationale and new therapeutic strategies}

The promise of TOR-KIs and PI3K/TOR-KIs. The recognition that rapalogs have limited substrate-specific efficacy and cause feedback activation of several oncogenic pathways has fueled the development of TOR-KIs and PI3K/TOR-KIs. Several of these are currently in phase I/II trials (Tables 2 and 3 ) or in preclinical development with lead compound optimization underway. mTOR catalytic inhibitors, via inhibition of mTORC2, prevent feedback-mediated AKT activation that results from inhibition of only mTORC1. In addition to circumventing this consequence of rapalog-mediated PI3K activation, several other mechanisms underlie the greater potential efficacy of these newer agents.

TOR-KIs cause more potent and durable inhibition of mTORC1 than rapalogs and hence more effectively inhibit protein synthesis. The mechanistic reasons for this are unclear. In a majority of cancer lines, rapalogs fail to inhibit protein synthesis due to weak or only transient inhibition of mTORC1mediated 4EBP1 phosphorylation (92). TOR-KIs, including WYE354 and WYE132 (Pfizer) (112), PP30 and PP242 (INK-128, Intellikine) (91), AZD8055 (AstraZeneca) (113), and Torin 1 (114), all inhibit protein synthesis with greater potency, due in part to greater inhibition of mTORC1 action on 4EBP1. Potential contributions of mTORC2 to protein synthesis via AKT/ GSK3- $\beta$ and PKC are also obviated by these drugs. 


\section{Table 2}

TOR-KI clinical development status

\begin{tabular}{|c|c|c|c|c|}
\hline Drug, company & Phase & Start date & Planned accrual & Development status ${ }^{A}$ \\
\hline OSI-027, OSI Pharmaceuticals & 1 & June 2008 & 75 & $\begin{array}{l}\text { Single agent (oral, dose escalation schedules) for solid tumors } \\
\text { or lymphomas (NCT00698243) }\end{array}$ \\
\hline \multirow[t]{3}{*}{ AZD8055, AstraZeneca } & $\mathrm{I} / \mathrm{II}$ & July 2008 & 100 & $\begin{array}{l}\text { Single agent (oral, twice daily) for advanced solid tumors } \\
\text { (NCT00731263) }\end{array}$ \\
\hline & I & September 2009 & 21 & $\begin{array}{l}\text { Single agent (oral, twice daily) for advanced solid tumors } \\
\text { in Japanese patients (NCT00973076) }\end{array}$ \\
\hline & $\mathrm{I} / \mathrm{II}$ & October 2009 & 80 & $\begin{array}{l}\text { Single agent (oral, dose escalation) for advanced hepatocellular } \\
\text { carcinoma in Asian patients (NCT00999882) }\end{array}$ \\
\hline \multirow[t]{2}{*}{ INK128, Intellikine } & I & December 2009 & 30 & $\begin{array}{l}\text { Single agent (oral dose escalation) for advanced solid malignancies } \\
\text { (NCT01058707) }\end{array}$ \\
\hline & I & June 2010 & 56 & $\begin{array}{l}\text { Single agent (oral dose escalation) for relapsed or refractory } \\
\text { multiple myeloma or Waldenström macroglobulinemia } \\
\text { (NCT01118689) }\end{array}$ \\
\hline
\end{tabular}

AThe ClinicalTrials.gov identifier is shown in parentheses.

Most cancers show strong activation of glycolysis, which contributes to cell survival in hypoxic and energy-poor environments. This shift to glycolytic over oxidative metabolism is mediated in part through AKT-dependent activation of glucose transporter 1 (Glut1). Lactate accumulation and acidosis activate HIF1 $\alpha$ and HIF $2 \alpha$, which drive transcription of glycolytic regulators (115, 116). TOR-KIs may more strongly oppose glycolysis than rapamycin (112) due to the lack of feedback activation of PI3K-driven $\mathrm{AKT}$ and due to their direct inhibition of mTORC2 leading to loss of AKT-dependent Glut1 accumulation. This may contribute importantly to the greater antitumor effects demonstrated in xenograft tumors treated with these compounds (112).

The increase in biomass of any malignant tumor requires lipid biosynthesis for cell membrane synthesis and lipid-based energy metabolism. In addition, many lipid-modified molecules regulate cellular signaling. It has recently come to light that GSK3- $\beta$-mediated phosphorylation targets for degradation a class of lipogenic transcription factors known as sterol-responsive element-binding proteins (SREBPs) $(117,118)$. PI3K/mTORC2-mediated AKT activation, by inhibiting GSK3- $\beta$, stabilizes the SREBPs to promote lipogenesis. In addition, ATP citrate lyase (ACL), a critical regulator of fatty acid synthesis, is phosphorylated and activated by AKT $(119,120)$. TOR-KIs and PI3K/TOR-KIs would thus, through their more potent inhibition of AKT than rapalogs, oppose lipid biosynthetic processes contributing to the selective loss of rapidly proliferating tumor cells $(32,121)$.

The TOR-KIs all cause greater cell cycle inhibition and $\mathrm{G}_{1}$ arrest in preclinical studies than rapamycin $(91,112-114,122)$. TOR-KIs not only inhibit mTORC1-dependent cyclin D1 translation, but also block AKT-mediated activation of cyclin D1 transcription (112). Furthermore, they more powerfully oppose the action of AKT via inhibition of GSK3- $\beta$ to stabilize cyclin D1 and cyclin E $(33,35)$. In addition, mTORC $1 / 2$ inhibition would more effectively block AKT- and SGK1-mediated phosphorylation of p27, reversing its cytoplasmic mislocalization and leading to more effective cyclin-CDK2 inhibition (123).

An additional benefit of mTORC1/2 inhibition may be to impair tumor cell invasion and metastatic potential. The inhibition of AKT/SGK1/RSK1-mediated p27 phosphorylation by TOR-KIs and PI3K/TOR-KIs, in addition to restoring nuclear p27 localization, would also abrogate the pro-oncogenic function acquired when p27pT198 binds RhoA, inhibits actin stability, and activates tumor cell motility and metastasis (63).

It is noteworthy that several of the pure TOR-KIs appear to induce apoptosis $(112)$ or autophagy $(113,114)$, while rapamycin does not. This in part reflects more potent inhibition of AKT, whose antiapoptotic effects are legion (13). In addition to inhibiting protein and lipid biosynthesis, mTORC1/2 inhibitors also have potent antiangiogenic effects. This was shown for Palomid 529 in preclinical in vivo models (124) and may result from more potent inhibition of hypoxia-induced HIF1 $\alpha$ and HIF $2 \alpha$ activation and reduced VEGF production (112). Recent work has shown that HIF $2 \alpha$ critically mediates cancer cell-autonomous growth through increased RTK expression (125). More potent inhibition of HIF $2 \alpha$ production would oppose RTK accumulation and growth factor independence (125), constituting yet another potential mechanism for the greater efficacy of TOR-KIs over rapalogs.

Despite promising preclinical and early clinical results with TOR-KIs, resistance to TOR-KIs could still arise via feedback PI3K activation. Despite the loss of mTORC2-mediated S473 phosphorylation of AKT in cells treated with a TOR-KI, mTORC1 inhibition would still promote feedback activation of PI3K- and PDK1-driven phosphorylation of AKT at T308. Constitutively T308-phosphorylated AKT shows modest substrate-dependent action without S473 phosphorylation; this may attenuate the therapeutic efficacy of TOR-KIs (91). Furthermore, the loss of mTORC1-mediated IRS feedback might activate PI3K effectors other than AKT. These molecular insights have stimulated the development of PI3K/TOR-KIs (Table 3). These new PI3K/TORKIs have shown powerful effects in xenograft models of breast cancer (126-129), pancreatic cancer (130), melanoma (131), multiple myeloma (132), glioma $(129,133)$, RCC (134), and acute myeloid leukemia (AML) (135). Like the TOR-KIs, many dual PI3K/TOR-KIs strongly induce apoptosis $(128,129,132,134,135)$ and/or autophagy (133). Several also show notable antiangiogenic properties, with significant reduction of xenograft neovascularization $(131,133)$. 
Table 3

PI3K/TOR-KI clinical development status

\begin{tabular}{|c|c|c|c|c|}
\hline Drug, company & Phase & Start date & Planned accrual & Development status ${ }^{A}$ \\
\hline \multirow[t]{2}{*}{ BEZ235/NVP-BEZ235, Novartis } & I/II & December 2006 & 80 & $\begin{array}{l}\text { Single agent (oral dose escalation), phase I/II for advanced } \\
\text { solid tumors/phase II for advanced breast cancer } \\
\text { (NCT00620594) }\end{array}$ \\
\hline & I & October 2010 & 30 & $\begin{array}{l}\text { Single agent (oral dose to determine MTD), Phase I for } \\
\text { advanced solid tumors (NCT01195376) }\end{array}$ \\
\hline \multirow[t]{2}{*}{ BGT226, Novartis } & $\mathrm{I} / \mathrm{II}$ & December 2007 & 57 & $\begin{array}{l}\text { Single agent (oral) for phase I for advanced solid tumors; } \\
\text { phase II for advanced breast cancer (NCT00600275) }\end{array}$ \\
\hline & I & November 2008 & 57 & Phase I for advanced solid tumors (NCT00742105) \\
\hline \multirow[t]{4}{*}{ XL765, Exelixis } & 1 & June 2007 & 75 & $\begin{array}{l}\text { Single agent (oral, once or twice daily) for solid tumors } \\
\text { (NCT00485719) }\end{array}$ \\
\hline & I & October 2008 & 80 & For NSCLC + erlotinib (NCT00777699) \\
\hline & 1 & September 2008 & 80 & For gliomas + temozolomide (NCT00704080) \\
\hline & $\mid / I I$ & May 2010 & 124 & For breast cancer + letrozole (NCT01082068) \\
\hline \multirow[t]{2}{*}{ GDC-0980, Genentech } & I & April 2009 & 63 & $\begin{array}{l}\text { Single agent (oral dose escalation) for non-Hodgkin } \\
\text { lymphoma/solid tumors (NCT00854126) }\end{array}$ \\
\hline & I & March 2009 & 75 & $\begin{array}{l}\text { Single agent (oral dose escalation) for non-Hodgkin } \\
\text { lymphoma/solid tumors (NCT00854152) }\end{array}$ \\
\hline GSK2126458, GlaxoSmithKline & I & August 2009 & 70 & $\begin{array}{l}\text { Single agent (oral dose escalation) for solid tumors } \\
\text { or lymphoma (NCT00972686) }\end{array}$ \\
\hline PF-04691502, Pfizer & I & December 2009 & 75 & $\begin{array}{l}\text { Single agent (oral dose escalation) for solid tumors } \\
\text { (NCT00927823) }\end{array}$ \\
\hline PF-05212384 (PKI-587), Pfizer & 1 & November 2009 & 85 & $\begin{array}{l}\text { Single agent (i.v. dose escalation) for solid tumors } \\
\text { (NCT00940498) }\end{array}$ \\
\hline
\end{tabular}

AThe ClinicalTrials.gov identifier is shown in parentheses. MTD, maximum tolerated dose; NSCLC, non-small cell lung cancer.

Together, these data indicate that relative to rapalogs, TOR-KIs and PI3K/TOR-KIs have the potential to more profoundly inhibit protein and lipid biosynthesis, as well as coordinate arrest of cell growth and cell cycle. In addition, they more effectively oppose angiogenesis, tumor invasion, metastasis, and survival.

PI3K/TOR-KIs and TOR-KIs in clinical trials. Several PI3K/TORKIs and TOR-KIs have entered clinical trials. The drugs, date of trial initiation, disease sites treated, and planned trial accrual are listed in Tables 2 and 3. This information is largely unpublished and comes from meeting reports of 2009 and 2010 (American Association of Cancer Research [AACR], San Antonio Breast Cancer Symposium [SABCS], European Organisation for Research and Treatment of Cancer [EORTC], and the American Society of Clinical Oncology [ASCO]) and from postings at ClinicalTrials.gov. Phase I trials of Novartis's PI3K/TOR-KIs, BEZ235 and BGT226, in advanced solid tumors began in 2006 and 2007, respectively. The BGT226 trial ended in 2009, and this drug will not be developed further, since BEZ235 is both more potent and more bioavailable. No dose-limiting toxicities have been reported for BEZ235, and mild adverse events (including nausea, vomiting, diarrhea, anemia, and anorexia) were manageable and reversible upon drug withdrawal. BEZ235 is pharmacodynamically active, exhibiting dose- and schedule-dependent PI3K inhibition (136). A phase I dose escalation study of XL765 (Exelixis) has shown good tolerability, with adverse effects including diarrhea, anorexia, rash, and mild elevations of postprandial insulin lev- els without effects on glycemia (137). This drug yielded marked disease stabilization in advanced solid tumors. In 2009 and early 2010, additional phase I trials of PI3K/TOR-KIs were initiated with GSK2126458 (GlaxoSmithKline), GDC0980 (Genentech), and PF-04691502 and PF-0521384 (Pfizer).

TOR-KIs have also entered clinical trials (Table 2), and additional lead compounds are in development. Phase I trials of OSI-027 (OSI Pharmaceuticals) and AZD8055 (AstraZeneca) in solid tumors and lymphoma were initiated in mid-2008, and the latter has moved to phase II trials in endometrial cancer. As a single agent, OSI-027 has shown preliminary evidence of pharmacodynamic activity, as assessed by reduction of phospho-4EBP1; it has also been well tolerated, and dose escalation studies are ongoing (138). OSI-027 is also being tested with the EGFR inhibitor erlotinib for non-small cell lung cancers and with temozolamide for gliomas.

PI3K inhibitors in cancer therapy. While they are not within the focus of this mTOR review, we would be remiss not to mention the development of a number of pure PI3K inhibitors. These compounds have been extensively reviewed elsewhere $(139,140)$. As for the TOR-KIs and PI3K/TOR-KIs, early preclinical studies and clinical trials have been promising, showing tumor growth inhibition in vitro and in vivo and favorable tolerability profiles. PI3K inhibitors currently in clinical trials include XL147 (as monotherapy in solid tumors or in combination with erlotinib or carboplatin/paclitaxel), NVP-BKM120, PX-866, GSK1059615 (all as monotherapy in solid tumors), and CAL-101 (as monotherapy 
in chronic lymphocytic leukemia, non-Hodgkin lymphoma, and acute myelogenous leukemia). Continued development of these compounds, and others that have yet to enter the clinic, will be important as they may complement the action of TOR-KIs and show synergies with other targeted therapies.

Biomarkers for Rapalog and TOR-KI patient selection. Identification of reliable biomarkers to assist in patient selection and to monitor treatment response is of paramount importance. HER2 amplification in breast cancer; overexpression of other RTKs, PTEN loss, PIK3CA mutations, elevated levels of phosphorylated AKT in many human cancers; cyclin D1 overexpression due to chromosomal translocations in mantle cell lymphoma; and von Hippel-Lindau tumor suppressor $(V H L)$ loss in renal cell cancers and Kaposi sarcoma have been identified in preclinical models as putative predictors of rapalog response (141-144). However, the use of PTEN and PIK$3 C A$ mutations and AKT phospho-status for predicting rapalog sensitivity has not been fully validated in clinic (145-150). Interestingly, one recent study showed that either PI3K activation or PTEN loss predicted enhanced susceptibility to everolimus in cancer cell lines, but this was abrogated if activating KRAS or BRAF mutations were also present (151). These results were validated in a small cohort of patients with advanced solid tumors: tumors showing PTEN loss and KRAS activation had minimal benefit from everolimus (151).

To date, attempts to identify and standardize biomarkers of rapalog response have been largely unsuccessful. The notion that pathway activation or "oncogene addiction" predicates response to pathway inhibition has not always been borne out. This may reflect the complexity of the PI3K/mTOR signaling network and the existence of feedback loops. Predictive factor studies accompanying early trials with rapalogs often had woefully too few tumor numbers to achieve significance (70), and technological challenges limit application of phosphoprotein-based immunohistochemistry (IHC) in human tumor specimens. Moreover, analysis of fixed, paraffin-embedded primary tumor specimens may have limited predictive ability for drug responses in metastatic disease due to tumor evolution over time, emphasizing the importance of clinical trial design with real-time tumor analysis. The recently attempted use of genomic methods to identify signaling pathway activation holds promise but requires refinement for clinical application.

Although most predictive biomarker studies have had too few samples for clinical prediction, IHC and genomic analysis of putative drug targets have illuminated drug mechanism. The recent appreciation that rapamycin is a substrate-specific mTORC1 inhibitor, causing transient, if any, 4EBP1 inhibition $(90,91,112)$, illuminates why S6K1 and ribosomal protein S6 (S6) phospho-status does not correlate with rapamycin response in preclinical models (149) and is unlikely to predict rapamycin sensitivity in humans. The observed activation of phosphorylated AKT in post-rapalog treatment tumor samples from clinical trials (94) confirmed the importance of feedback mechanisms in resistance and fueled the discovery of new-generation TOR-KIs. In future trials, the phosphorylation status of AKT, 4EBP1, S6K1, and S6 and the presence of PTEN or PIK3CA muta- tions may prove to be useful response predictors for PI3K/TOR-KIs and TOR-KIs. Moreover, cytoplasmic p27, which is readily detected by IHC, may be a powerful indicator of PI3K/mTOR activation and susceptibility to PI3K/TOR-KIs. Clinical trials with accompanying histopathologic evaluation of pre- and post-treatment effects in skin, peripheral blood mononuclear cells, and tumor samples will help define the most biologically relevant targets, ensuring that these agents are delivered to patients most likely to respond.

\section{Concluding remarks and future directions}

The last decade has witnessed a growing appreciation of the complexity of PI3K/mTOR signaling and of the potential of mTORtargeted anticancer therapies. Despite the limited efficacy of rapalogs, these drugs have shown clear benefit in mantle cell lymphomas, RCC, and TSC-related tumors, for which few therapeutic options exist. Studies of rapalog action in cell lines and patients have revealed mechanisms underlying their limited clinical impact, including substrate-selective inhibition of mTORC1 and activation of feedback loops. These insights have prompted the development of direct mTOR kinase inhibitors.

It remains to be determined whether catalytic inhibition of mTOR and/or PI3K will also give rise to feedback loop activation via novel, as-yet-undiscovered autoregulatory mechanisms. This highlights the need for ongoing design of clinical trials with molecular correlative studies utilizing tumor biopsies. As tolerability profiles for new TOR-KIs and PI3K/TOR-KIs are assessed, correlative analyses are required to identify clinically feasible and reliable biomarkers of response and of the emergence of drug resistance.

While PI3K/TOR-KIs and TOR-KIs may prove more potent as single agents than rapalogs, their greatest efficacy may lie in combinations with other pathway inhibitors. It is increasingly clear that antitumor efficacy and response duration with inhibitors of a single kinase are frequently limited by parallel signaling, bypass pathway activation, or feedback activation of mitogenic pathways. Molecular arguments can be made for testing the new TOR-KIs together with MEK or Src inhibitors, farnesyl transferase inhibitors, EGFR- or HER2-directed therapies, antiangiogenic agents, and, for ER-positive breast cancers, hormonal agents. As signaling complexity in cancers is better understood, therapeutic strategies to inhibit mTOR together with other pivotal biosynthetic, proliferation, and survival pathways hold significant promise.

\section{Acknowledgments}

We apologize to those whose contributions were not quoted due to space limitations and thank Vinnay Jain and Preeti Chaudhary for data on developing drugs. This work was supported by NIH-NCI 5-R01CA-105118-04 and by the Doris Duke Charitable Foundation.

Address correspondence to: Joyce M. Slingerland, BFBCI, Biomedical Research Building, Room 708 (C227), 1501 NW 10th Avenue, Miami, Florida 33136, USA. Phone: 305.243.6788; Fax: 305.243.4787; E-mail: jslingerland@med.miami.edu.
1. Kim DH, et al. mTOR interacts with raptor to form
a nutrient-sensitive complex that signals to the cell
growth machinery. Cell. 2002;110(2):163-175.
2. Vezina C, Kudelski A, Sehgal SN. Rapamycin (AY-
22,989), a new antifungal antibiotic. I. Taxonomy
of the producing streptomycete and isolation
of the active principle. J Antibiot (Tokyo). 1975 ;
28(10):721-726.
3. Sarbassov DD, et al. Rictor, a novel binding partner of $\mathrm{mTOR}$, defines a rapamycin-insensitive and raptor-independent pathway that regulates the cytoskeleton. Curr Biol. 2004;14(14):1296-1302.

4. Sarbassov DD, et al. Prolonged rapamycin treatment inhibits mTORC2 assembly and Akt/PKB. Mol Cell. 2006;22(2):159-168.

5. Peterson TR, et al. DEPTOR is an mTOR inhibitor frequently overexpressed in multiple myeloma cells and required for their survival. Cell.
2009;137(5):873-886.

6. Liu P, Cheng H, Roberts TM, Zhao JJ. Targeting the phosphoinositide 3-kinase pathway in cancer. Nat Rev Drug Discov. 2009;8(8):627-644.

7. Chiang GG, Abraham RT. Targeting the mTOR signaling network in cancer. Trends $\mathrm{Mol} \mathrm{Med}$. 2007; 13(10):433-442.

8. Sarbassov DD, Guertin DA, Ali SM, Sabatini DM. Phosphorylation and regulation of 
Akt/PKB by the rictor-mTOR complex. Science. 2005;307(5712):1098-1101.

9. Hresko RC, Mueckler M. mTOR.RICTOR is the Ser473 kinase for Akt/protein kinase B in 3T3-L1 adipocytes. J Biol Chem. 2005;280(49):40406-40416.

10. Hong F, Larrea MD, Doughty C, Kwiatkowski DJ, Squillace R, Slingerland JM. mTOR-raptor binds and activates SGK1 to regulate $\mathrm{P} 27$ phosphorylation. Mol Cell. 2008;30(6):701-711.

11. Garcia-Martinez JM, Alessi DR. mTOR complex 2 (mTORC2) controls hydrophobic motif phosphorylation and activation of serum- and glucocorticoid-induced protein kinase 1 (SGK1). Biochem J. 2008;416(3):375-385

12. Frodin M, Gammeltoft S. Role and regulation of $90 \mathrm{kDa}$ ribosomal S6 kinase (RSK) in signal transduction. Mol Cell Endocrinol. 1999 151(1-2):65-77.

13. Manning BD, Cantley LC. AKT/PKB signaling: navigating downstream. Cell. 2007;129(7):1261-1274.

14. Tessier M, Woodgett JR. Serum and glucocorticoid-regulated protein kinases: variations on a theme. J Cell Biochem. 2006;98(6):1391-1407.

15. Tee AR, Manning BD, Roux PP, Cantley LC, Blenis J. Tuberous sclerosis complex gene products, Tuberin and Hamartin, control mTOR signaling by acting as a GTPase-activating protein complex toward Rheb. Curr Biol. 2003;13(15):1259-1268.

16. Potter CJ, Pedraza LG, Xu T. Akt regulates growth by directly phosphorylating Tsc2. Nat Cell Biol. 2002;4(9):658-665.

17. Manning BD, Tee AR, Logsdon MN, Blenis J, Cantley LC. Identification of the tuberous sclerosis complex-2 tumor suppressor gene product tuberin as a target of the phosphoinositide 3-kinase/akt pathway. Mol Cell. 2002;10(1):151-162.

18. Inoki K, Li Y, Zhu T, Wu J, Guan KL. TSC2 is phosphorylated and inhibited by Akt and suppresses mTOR signalling. Nat Cell Biol. 2002;4(9):648-657.

19. Ma L, Chen Z, Erdjument-Bromage H, Tempst P, Pandolfi PP. Phosphorylation and functional inactivation of TSC2 by Erk implications for tuberous sclerosis and cancer pathogenesis. Cell. 2005;121(2):179-193.

20. Roux PP, Ballif BA, Anjum R, Gygi SP, Blenis J Tumor-promoting phorbol esters and activated Ras inactivate the tuberous sclerosis tumor suppressor complex via p90 ribosomal S6 kinase. Proc Natl Acad Sci U S A. 2004;101(37):13489-13494.

21. Goncharova EA, Krymskaya VP. Pulmonary lymphangioleiomyomatosis (LAM): progress and current challenges. J Cell Biochem. 2008;103(2):369-382.

22. Carriere A, et al. Oncogenic MAPK signaling stimulates mTORC1 activity by promoting RSKmediated raptor phosphorylation. Curr Biol. 2008;18(17):1269-1277.

23. Brugarolas J, et al. Regulation of mTOR function in response to hypoxia by REDD1 and the TSC1/TSC2 tumor suppressor complex. Genes Dev. 2004;18(23):2893-2904.

24. Sofer A, Lei K, Johannessen CM, Ellisen LW. Regulation of mTOR and cell growth in response to energy stress by REDD1. Mol Cell Biol. 2005; 25(14):5834-5845

25. DeYoung MP, Horak P, Sofer A, Sgroi D, Ellisen LW. Hypoxia regulates TSC1/2-mTOR signaling and tumor suppression through REDD1-mediated 14-3-3 shuttling. Genes Dev. 2008;22(2):239-251.

26. Inoki K, Zhu T, Guan KL. TSC2 mediates cellular energy response to control cell growth and survival. Cell. 2003;115(5):577-590.

27. Woods A, et al. LKB1 is the upstream kinase in the AMP-activated protein kinase cascade. Curr Biol. 2003;13(22):2004-2008.

28. Shaw RJ, et al. The LKB1 tumor suppressor negatively regulates mTOR signaling. Cancer Cell. 2004;6(1):91-99.

29. Feng Z, Zhang H, Levine AJ, Jin S. The coordinate regulation of the $\mathrm{p} 53$ and $\mathrm{mTOR}$ pathways in cells. Proc Natl Acad Sci U S A. 2005;102(23):8204-8209.

30. Gwinn DM, et al. AMPK phosphorylation of raptor mediates a metabolic checkpoint. Mol Cell. 2008;30(2):213-226.

31. Hay N, Sonenberg N. Upstream and downstream of mTOR. Genes Dev. 2004;18(16):1926-1945.

32. Laplante M, Sabatini DM. An emerging role of mTOR in lipid biosynthesis. Curr Biol. 2009; 19(22):R1046-R1052.

33. Liang J, Slingerland JM. Multiple roles of the PI3K/ PKB (Akt) pathway in cell cycle progression. Cell Cycle. 2003;2(4):339-345.

34. Pearce LR, Komander D, Alessi DR. The nuts and bolts of AGC protein kinases. Nat Rev Mol Cell Biol. 2010;11(1):9-22.

35. Diehl JA, Cheng M, Roussel MF, Sherr CJ. Glycogen synthase kinase-3beta regulates cyclin D1 proteolysis and subcellular localization. Genes Dev. 1998;12(22):3499-3511

36. Medema RH, Kops GJ, Bos JL, Burgering BM. AFXlike Forkhead transcription factors mediate cellcycle regulation by Ras and PKB through p27kip1. Nature. 2000;404(6779):782-787.

37. Zhou BP, Liao Y, Xia W, Spohn B, Lee MH, Hung MC. Cytoplasmic localization of p21Cip1/WAF1 by Akt-induced phosphorylation in HER-2/neu-overexpressing cells. Nat Cell Biol. 2001;3(3):245-252.

38. Engelman JA. Targeting PI3K signalling in cancer: opportunities, challenges and limitations. Nat Rev Cancer. 2009;9(8):550-562.

39. Huang $\mathrm{CH}$, et al. The structure of a human p110alpha/p85alpha complex elucidates the effects of oncogenic PI3Kalpha mutations. Science. 2007; 318(5857):1744-1748.

40. Roux PP, Blenis J. ERK and p38 MAPK-activated protein kinases: a family of protein kinases with diverse biological functions. Microbiol Mol Biol Rev. 2004;68(2):320-344.

41. Huang J, Manning BD. The TSC1-TSC2 complex: a molecular switchboard controlling cell growth. Biochem J. 2008;412(2):179-190.

42. Hornigold N, Devlin J, Davies AM, Aveyard JS, Habuchi T, Knowles MA. Mutation of the 9q34 gene TSC1 in sporadic bladder cancer. Oncogene. 1999;18(16):2657-2661.

43. Knowles MA, Habuchi T, Kennedy W, CuthbertHeavens D. Mutation spectrum of the $9 \mathrm{q} 34$ tuberous sclerosis gene TSC1 in transitional cell carcinoma of the bladder. Cancer Res. 2003;63(22):7652-7656.

44. Platt FM, Hurst CD, Taylor CF, Gregory WM, Harnden P, Knowles MA. Spectrum of phosphatidylinositol 3-kinase pathway gene alterations in bladder cancer. Clin Cancer Res. 2009;15(19):6008-6017.

45. Wienecke R, Guha A, Maize JC Jr, Heideman RL, DeClue JE, Gutmann DH. Reduced TSC2 RNA and protein in sporadic astrocytomas and ependymomas. Ann Neurol. 1997;42(2):230-235.

46. Jiang WG, et al. Tuberin and hamartin are aberrantly expressed and linked to clinical outcome in human breast cancer: the role of promoter methylation of TSC genes. Eur J Cancer. 2005;41(11):1628-1636

47. Chakraborty S, Mohiyuddin SM, Gopinath KS, Kumar A. Involvement of TSC genes and differential expression of other members of the mTOR signaling pathway in oral squamous cell carcinoma. BMC Cancer. 2008;8:163.

48. Xu Z, et al. Aberrant expression of TSC2 gene in the newly diagnosed acute leukemia. Lenk Res. 2009;33(7):891-897.

49. Johannessen CM, Reczek EE, James MF, Brems H, Legius E, Cichowski K. The NF1 tumor suppressor critically regulates TSC2 and mTOR. Proc Natl Acad SciUS A. 2005;102(24):8573-8578.

50. Zheng B, et al. Oncogenic B-RAF negatively regulates the tumor suppressor LKB1 to promote melanoma cell proliferation. Mol Cell. 2009;33(2):237-247.

51. Esteve-Puig R, Canals F, Colome N, Merlino G,
Recio JA. Uncoupling of the LKB1-AMPKalpha energy sensor pathway by growth factors and oncogenic BRAF. PLoS One. 2009;4(3):e4771.

52. Menon S, Manning BD. Common corruption of the mTOR signaling network in human tumors. Oncogene. 2008;27(suppl 2):S43-S51.

53. Khamzina L, Veilleux A, Bergeron S, Marette A. Increased activation of the mammalian target of rapamycin pathway in liver and skeletal muscle of obese rats: possible involvement in obesity-linked insulin resistance. Endocrinology. 2005;146(3):1473-1481.

54. Newgard CB, et al. A branched-chain amino acidrelated metabolic signature that differentiates obese and lean humans and contributes to insulin resistance. Cell Metab. 2009;9(4):311-326.

55. Shaw RJ, et al. The kinase LKB1 mediates glucose homeostasis in liver and therapeutic effects of metformin. Science. 2005;310(5754):1642-1646.

56. Dann SG, Selvaraj A, Thomas G. mTOR Complex1S6K1 signaling: at the crossroads of obesity, diabetes and cancer. Trends Mol Med. 2007;13(6):252-259.

57. Mackenzie MJ, Ernst S, Johnson C, Winquist E. A phase I study of temsirolimus and metformin in advanced solid tumours [published online ahead of print October 27, 2010]. Invest New Drugs. doi:10.1007/s10637-010-9570-8.

58. Liang J, et al. PKB/Akt phosphorylates p27, impairs nuclear import of p27 and opposes p27-mediated G1 arrest. Nat Med. 2002;8(10):1153-1160.

59. Motti ML, De Marco C, Califano D, Fusco A, Viglietto G. Akt-dependent T198 phosphorylation of cyclin-dependent kinase inhibitor p27(kip1) in breast cancer. Cell Cycle. 2004;3(8):1074-1080.

60. Fujita N, Sato S, Tsuruo T. Phosphorylation of $\mathrm{p} 27 \mathrm{Kip} 1$ at threonine 198 by $\mathrm{p} 90$ ribosomal protein S6 kinases promotes its binding to 143-3 and cytoplasmic localization. J Biol Chem. 2003;278(49):49254-49260.

61. Liang J, et al. The energy sensing LKB1-AMPK pathway regulates $\mathrm{p} 27$ (kip 1$)$ phosphorylation mediating the decision to enter autophagy or apoptosis. Nat Cell Biol. 2007;9(2):218-224.

62. Kossatz U, et al. C-terminal phosphorylation controls the stability and function of $\mathrm{p} 27 \mathrm{kip} 1$. EMBOJ. 2006;25(21):5159-5170.

63. Larrea MD, et al. RSK1 drives p27Kip1 phosphorylation at T198 to promote RhoA inhibition and increase cell motility. Proc Natl Acad Sci U S A. 2009;106(23):9268-9273.

64. Besson A, Gurian-West M, Schmidt A, Hall A, Roberts JM. p27Kip1 modulates cell migration through the regulation of RhoA activation. Genes Dev. 2004;18(8):862-876.

65. Denicourt C, Saenz CC, Datnow B, Cui XS, Dowdy SF. Relocalized p27(KiP1) tumor suppressor functions as a cytoplasmic metastatic oncogene in melanoma. Cancer Res. 2007;67(19):9238-9243.

66. Vasudevan KM, et al. AKT-independent signaling downstream of oncogenic PIK3CA mutations in human cancer. Cancer Cell. 2009;16(1):21-32.

67. Hidalgo $\mathrm{M}$, et al. A phase I and pharmacokinetic study of temsirolimus (CCI-779) administered intravenously daily for 5 days every 2 weeks to patients with advanced cancer. Clin Cancer Res. 2006;12(19):5755-5763.

68. Yee KW, et al. Phase I/II study of the mammalian target of rapamycin inhibitor everolimus (RAD001) in patients with relapsed or refractory hematologic malignancies. Clin Cancer Res. 2006; 12(17):5165-5173.

69. Atkins MB, et al. Randomized phase II study of multiple dose levels of CCI-779, a novel mammalian target of rapamycin kinase inhibitor, in patients with advanced refractory renal cell carcinoma. J Clin Oncol. 2004;22(5):909-918.

70. Meric-Bernstam F, Gonzalez-Angulo AM. Targeting the mTOR signaling network for cancer therapy. J Clin Oncol. 2009;27(13):2278-2287. 
71. Hudes G, et al. Temsirolimus, interferon alfa, or both for advanced renal-cell carcinoma. $N$ Engl J Med. 2007;356(22):2271-2281.

72. Motzer RJ, et al. Efficacy of everolimus in advanced renal cell carcinoma: a double-blind, randomised, placebo-controlled phase III trial. Lancet. 2008; 372(9637):449-456.

73. Hess G, et al. Phase III study of patients with relapsed, refractory mantle-cell lymphoma treated with temsirolimus compared with investigator's choice therapy. J Clin Oncol. 2009;27(23):3822-3829.

74. Ansell SM, et al. Low-dose, single-agent temsirolimus for relapsed mantle cell lymphoma: a phase 2 trial in the North Central Cancer Treatment Group. Cancer. 2008;113(3):508-514.

75. Witzig TE, et al. Phase II trial of single-agent temsirolimus (CCI-779) for relapsed mantle cell lymphoma. J Clin Oncol. 2005;23(23):5347-5356.

76. Smith SM, et al. Activity of single agent temsirolimus (CCI-779) in non-mantle-cell non-Hodgkin lymphoma subtypes. J Clin Oncol. 2010;28(31):4740-4746.

77. Chawla SP, et al. Updated results of a phase II trial of AP23573, a novel mTOR inhibitor, in patients (pts) with advanced soft tissue or bone sarcomas. JClin Oncol. 2006;24(suppl):521s, abstr 9505.

78. Colombo $\mathrm{N}$, et al. A phase II trial of the mTOR inhibitor AP23573 as a single agent in advanced endometrial cancer. J Clin Oncol. 2007; 25(suppl):278s, abstr 5516

79. Slomovitz BM, et al. A phase II study of oral mammalian target of rapamycin (mTOR) inhibitor, RAD001 (everolimus) in patients with recurrent endometrial carcinoma (EC) J Clin Oncol. 2008;26(suppl):293s, abstr 5502.

80. Tabernero J, et al. Dose- and schedule-dependent inhibition of the mammalian target of rapamycin pathway with everolimus: a phase I tumor pharmacodynamic study in patients with advanced solid tumors. J Clin Oncol. 2008;26(10):1603-1610.

81. Herry I, Neukirch C, Debray MP, Mignon F, Crestani B. Dramatic effect of sirolimus on renal angiomyolipomas in a patient with tuberous sclerosis complex. Eur J Intern Med. 2007;18(1):76-77.

82. Bissler JJ, et al. Sirolimus for angiomyolipoma in tuberous sclerosis complex or lymphangioleiomyomatosis. NEngl J Med. 2008;358(2):140-151.

83. Wienecke R, Fackler I, Linsenmaier U, Mayer K, Licht T, Kretzler M. Antitumoral activity of rapamycin in renal angiomyolipoma associated with tuberous sclerosis complex. Am J Kidney Dis. 2006;48(3):e27-e29.

84. Franz DN, et al. Rapamycin causes regression of astrocytomas in tuberous sclerosis complex. Ann Neurol. 2006;59(3):490-498.

85. Franz D, et al. Everolimus for subependymal giantcell astrocytomas (SEGAs) in tuberous sclerosis (TS). Presented at the 46th Annual Meeting of the American Society of Clinical Oncology. Abstract No. 2004. June 5, 2010.

86. Galanis E, et al. Phase II trial of temsirolimus (CCI-779) in recurrent glioblastoma multiforme: a North Central Cancer Treatment Group Study. J Clin Oncol. 2005;23(23):5294-5304.

87. Margolin K, et al. CCI-779 in metastatic melanoma: a phase II trial of the California Cancer Consortium. Cancer. 2005;104(5):1045-1048.

88. Chan S, et al. Phase II study of temsirolimus (CCI779), a novel inhibitor of mTOR, in heavily pretreated patients with locally advanced or metastatic breast cancer. J Clin Oncol. 2005;23(23):5314-5322.

89. Ellard SL, et al. Randomized phase II study comparing two schedules of everolimus in patients with recurrent/metastatic breast cancer: NCIC Clinical Trials Group IND.163. J Clin Oncol. 2009;27(27):4536-4541.

90. Choo AY, Yoon SO, Kim SG, Roux PP, Blenis J. Rapamycin differentially inhibits $\mathrm{S} 6 \mathrm{Ks}$ and 4E-BP1 to mediate cell-type-specific repression of mRNA translation. Proc Natl Acad Sci U S A. 2008;105(45):17414-17419.

91. Feldman ME, et al. Active-site inhibitors of mTOR target rapamycin-resistant outputs of mTORC1 and mTORC2. PLoS Biol. 2009;7(2):e38.

92. Choo AY, Blenis J. Not all substrates are treated equally: implications for mTOR, rapamycin-resistance and cancer therapy. Cell Cycle. 2009;8(4):567-572.

93. Harrington LS, et al. The TSC1-2 tumor suppressor controls insulin-PI3K signaling via regulation of IRS proteins. J Cell Biol. 2004;166(2):213-223.

94. O'Reilly KE, et al. mTOR inhibition induces upstream receptor tyrosine kinase signaling and activates Akt. Cancer Res. 2006;66(3):1500-1508.

95. Carracedo A, Pandolfi PP. The PTEN-PI3K pathway: of feedbacks and cross-talks. Oncogene. 2008;27(41):5527-5541

96. Zhang $\mathrm{H}$, et al. PDGFRs are critical for PI3K/Akt activation and negatively regulated by mTOR. $J$ Clin Invest. 2007;117(3):730-738

97. Dibble CC, Asara JM, Manning BD. Characterization of Rictor phosphorylation sites reveals direct regulation of mTOR complex 2 by S6K1. Mol Cell Biol. 2009;29(21):5657-5670.

98. Julien LA, Carriere A, Moreau J, Roux PP. mTORC1activated S6K1 phosphorylates Rictor on threonine 1135 and regulates mTORC2 signaling. Mol Cell Biol. 2010;30(4):908-921.

99. Carracedo A, et al. Inhibition of mTORC1 leads to MAPK pathway activation through a PI3K-dependent feedback loop in human cancer. J Clin Invest. 2008;118(9):3065-3074.

100. Mondesire WH, et al. Targeting mammalian target of rapamycin synergistically enhances chemotherapy-induced cytotoxicity in breast cancer cells. Clin Cancer Res. 2004;10(20):7031-7042.

101. Steelman LS, et al. Suppression of PTEN function increases breast cancer chemotherapeutic drug resistance while conferring sensitivity to $\mathrm{mTOR}$ inhibitors. Oncogene. 2008;27(29):4086-4095

102.Yao JC, et al. Efficacy of RAD001 (everolimus) and octreotide LAR in advanced low- to intermediategrade neuroendocrine tumors: results of a phase II study. J Clin Oncol. 2008;26(26):4311-4318.

103. Coleman KM, Smith CL. Intracellular signaling pathways: nongenomic actions of estrogens and ligand-independent activation of estrogen receptors. Front Biosci. 2001;6:D1379-D1391.

104.Sadler TM, Gavriil M, Annable T, Frost P, Greenberger LM, Zhang Y. Combination therapy for treating breast cancer using antiestrogen, ERA-923, and the mammalian target of rapamycin inhibitor, temsirolimus. Endocr Relat Cancer. 2006;13(3):863-873.

105. Beeram M, Tan QT, Tekmal RR, Russell D, Middleton A, deGraffenried LA. Akt-induced endocrine therapy resistance is reversed by inhibition of mTOR signaling. Ann Oncol. 2007;18(8):1323-1328.

106.deGraffenried LA, et al. Inhibition of mTOR activity restores tamoxifen response in breast cancer cells with aberrant Akt Activity. Clin Cancer Res. 2004;10(23):8059-8067.

107. Chow LWC, et al. Presented at the 29th Annual San Antonio Breast Cancer Symposium (December 1417, 2006, San Antonio, Texas, USA), Phase III study of temsirolimus with letrozole or letrozole alone in postmenopausal women with locally advanced or metastatic breast cancer.

108. Awada A, et al. The oral mTOR inhibitor RAD001 (everolimus) in combination with letrozole in patients with advanced breast cancer: results of a phase I study with pharmacokinetics. Eur J Cancer. 2008;44(1):84-91.

109.Baselga J, et al. Phase II randomized study of neoadjuvant everolimus plus letrozole compared with placebo plus letrozole in patients with estrogen receptor-positive breast cancer. J Clin Oncol. 2009;27(16):2630-2637.

110.Jerusalem GH. Maintenance with everolimus
(RAD001) and trastuzumab (T) after discontinuation of chemotherapy in patients (pts) with heavily pretreated HER2-positive metastatic breast cancer (MBC): pooled data of extension cohorts of phase Ib/II studies. J Clin Oncol. 2010;28(15 suppl):1041.

111. Wellbrock C, Hurlstone A. BRAF as therapeutic target in melanoma. Biochem Pharmacol. 2010; 80(5):561-567.

112.Yu K, et al. Biochemical, cellular, and in vivo activity of novel ATP-competitive and selective inhibitors of the mammalian target of rapamycin. Cancer Res. 2009;69(15):6232-6240.

113. Chresta CM, et al. AZD8055 is a potent, selective, and orally bioavailable ATP-competitive mammalian target of rapamycin kinase inhibitor with in vitro and in vivo antitumor activity. Cancer Res. 2010;70(1):288-298.

114. Thoreen CC, et al. An ATP-competitive mammalian target of rapamycin inhibitor reveals rapamycin-resistant functions of mTORC1. J Biol Chem. 2009;284(12):8023-8032.

115. Kroemer G, Pouyssegur J. Tumor cell metabolism: cancer's Achilles' heel. Cancer Cell. 2008; 13(6):472-482

116. DeBerardinis RJ, Lum JJ, Hatzivassiliou G, Thompson $\mathrm{CB}$. The biology of cancer: metabolic reprogramming fuels cell growth and proliferation. Cell Metab. 2008;7(1):11-20.

117. Porstmann T, et al. PKB/Akt induces transcription of enzymes involved in cholesterol and fatty acid biosynthesis via activation of SREBP. Oncogene. 2005;24(43):6465-6481.

118. Horton JD, Goldstein JL, Brown MS. SREBPs: activators of the complete program of cholesterol and fatty acid synthesis in the liver. J Clin Invest. 2002;109(9):1125-1131.

119. Berwick DC, Hers I, Heesom KJ, Moule SK, Tavare JM. The identification of ATP-citrate lyase as a protein kinase $\mathrm{B}(\mathrm{Akt})$ substrate in primary adipocytes. J Biol Chem. 2002;277(37):33895-33900.

120. Bauer DE, Hatzivassiliou G, Zhao F, Andreadis C, Thompson CB. ATP citrate lyase is an important component of cell growth and transformation. Oncogene. 2005;24(41):6314-6322.

121. Shor B, Gibbons JJ, Abraham RT, Yu K. Targeting mTOR globally in cancer: thinking beyond rapamycin. Cell Cycle. 2009;8(23):3831-3837.

122. Garcia-Martinez JM, et al. Ku-0063794 is a specific inhibitor of the mammalian target of rapamycin (mTOR). Biochem J. 2009;421(1):29-42.

123. Chu IM, Hengst L, Slingerland JM. The Cdk inhibitor P27 in human cancer: prognostic potential and relevance to anticancer therapy. Nat Rev Cancer. 2008;8(4):253-267.

124.Xue Q, Hopkins B, Perruzzi C, Udayakumar D, Sherris D, Benjamin LE. Palomid 529, a novel small-molecule drug, is a TORC1/TORC2 inhibitor that reduces tumor growth, tumor angiogenesis, and vascular permeability. Cancer Res. 2008;68(22):9551-9557.

125. Franovic A, Holterman CE, Payette J, Lee S. Human cancers converge at the HIF-2alpha oncogenic axis. Proc Natl Acad Sci U S A. 2009;106(50):21306-21311.

126. Schnell CR, et al. Effects of the dual phosphatidylinositol 3-kinase/mammalian target of rapamycin inhibitor NVP-BEZ235 on the tumor vasculature: implications for clinical imaging. Cancer Res. 2008;68(16):6598-6607.

127. Serra V, et al. NVP-BEZ235, a dual PI3K/mTOR inhibitor, prevents PI3K signaling and inhibits the growth of cancer cells with activating PI3K mutations. Cancer Res. 2008;68(19):8022-8030.

128. Brachmann SM, et al. Specific apoptosis induction by the dual PI3K/mTor inhibitor NVP-BEZ235 in HER2 amplified and PIK3CA mutant breast cancer cells. Proc Natl Acad Sci U S A. 2009;106(52):22299-22304.

129. Mallon R, et al. Antitumor efficacy profile of PKI-402, a dual phosphatidylinositol 3-kinase/mamma- 
lian target of rapamycin inhibitor. Mol Cancer Ther. 2010;9(4):976-984.

130.Cao P, Maira SM, Garcia-Echeverria C, Hedley DW. Activity of a novel, dual PI3-kinase/mTor inhibitor NVP-BEZ235 against primary human pancreatic cancers grown as orthotopic xenografts. BrJ Cancer. 2009;100(8):1267-1276.

131. Marone R, et al. Targeting melanoma with dual phosphoinositide 3-kinase/mammalian tar get of rapamycin inhibitors. Mol Cancer Res. 2009;7(4):601-613.

132.McMillin DW, et al. Antimyeloma activity of the orally bioavailable dual phosphatidylinositol 3 kinase/mammalian target of rapamycin inhibitor NVP-BEZ235. Cancer Res. 2009;69(14):5835-5842.

133.Liu TJ, et al. NVP-BEZ235, a novel dual phosphatidylinositol 3-kinase/mammalian target of rapamycin inhibitor, elicits multifaceted antitumor activities in human gliomas. Mol Cancer Ther. 2009;8(8):2204-2210.

134. Cho DC, et al. The efficacy of the novel dual PI3 kinase/mTOR inhibitor NVP-BEZ235 compared with rapamycin in renal cell carcinoma. Clin Cancer Res. 2010;16(14):3628-3638.

135. Park S, et al. PI-103, a dual inhibitor of Class IA phosphatidylinositide 3-kinase and mTOR, has antileukemic activity in AML. Lenkemia. 2008;22(9):1698-1706

136. Burris H, et al. First-in-human phase I study of the oral PI3K inhibitor BEZ235 in patients (pts) with advanced solid tumors. J Clin Oncol. 2010;28:3005. 137. Brana I, et al. A phase I dose-escalation study of the safety, pharmacokinetics (PK), and pharmacodynamics of XL765 (SAR245409), a PI3K/TORC1/ TORC2 inhibitor administered orally to patients (pts) with advanced malignancies. J Clin Oncol. 2010;28:3030.

138.Tan DS, et al. First-in-human phase I study exploring three schedules of OSI-027, a novel small molecule TORC1/TORC2 inhibitor, in patients with advanced solid tumors and lymphoma.J Clin Oncol. 2010;28:3006.

139. Markman B, Atzori F, Perez-Garcia J, Tabernero J, Baselga J. Status of PI3K inhibition and biomarker development in cancer therapeutics. Ann Oncol. 2010;21(4):683-691.

140. Marone R, Cmiljanovic V, Giese B, Wymann MP. Targeting phosphoinositide 3-kinase: moving towards therapy. Biochim Biophys Acta. 2008;1784(1):159-185.

141. Cho D, et al. Potential histologic and molecular predictors of response to temsirolimus in patients with advanced renal cell carcinoma. Clin Genitourin Cancer. 2007;5(6):379-385.

142.Iwenofu OH, Lackman RD, Staddon AP, Goodwin DG, Haupt HM, Brooks JS. Phospho-S6 ribosomal protein: a potential new predictive sarcoma marker for targeted mTOR therapy. Mod Pathol. 2008;21(3):231-237.

143. Duran I, et al. A phase II clinical and pharmacody- namic study of temsirolimus in advanced neuroendocrine carcinomas. BrJ Cancer. 2006;95(9):1148-1154.

144. Thomas GV, et al. Hypoxia-inducible factor determines sensitivity to inhibitors of mTOR in kidney cancer. Nat Med. 2006;12(1):122-127.

145. Podsypanina K, et al. An inhibitor of $\mathrm{mTOR}$ reduces neoplasia and normalizes $\mathrm{p} 70 / \mathrm{S} 6$ kinase activity in Pten+/- mice. Proc Natl Acad Sci U S A. 2001;98(18):10320-10325.

146. Neshat MS, et al. Enhanced sensitivity of PTENdeficient tumors to inhibition of FRAP/mTOR. Proc Natl Acad Sci U S A. 2001;98(18):10314-10319.

147. Shi Y, et al. Enhanced sensitivity of multiple myeloma cells containing PTEN mutations to CCI-779. Cancer Res. 2002;62(17):5027-5034.

148.deGraffenried LA, Fulcher L, Friedrichs WE, Grunwald V, Ray RB, Hidalgo M. Reduced PTEN expression in breast cancer cells confers susceptibility to inhibitors of the PI3 kinase/Akt pathway. Ann Oncol. 2004;15(10):1510-1516.

149. Noh WC, et al. Determinants of rapamycin sensitivity in breast cancer cells. Clin Cancer Res. 2004;10(3):1013-1023.

150.Bader AG, Kang S, Vogt PK. Cancer-specific mutations in PIK3CA are oncogenic in vivo. Proc Natl Acad Sci U S A. 2006;103(5):1475-1479.

151.Di NF, et al. Deregulation of the PI3K and KRAS signaling pathways in human cancer cells determines their response to everolimus. J Clin Invest. 2010;120(8):2858-2866 